\section{The influence of changes in hand temperature on the indirectly evoked electromyogram of the first dorsal interosseous muscle}

Aaron F. Kopman MD, Mona D. Justo MD, Moin U. Mallhi MD, Chinedu E. Abara MD, George G. Neuman MD
The evoked EMG response commonly decreases in amplitude during the first few minutes of anaesthesia. The purpose of this study was to determine if a relationship exists between changes in hand temperature, which are known to occur with induction of anaesthesia, and drift in the EMG signal. The indirectly evoked response of the 1st dorsal interosseous muscle was measured using a Datex (10) Relaxograph ${ }^{\circledR}$ in 15 patients undergoing elective surgery. The test arm was wrapped in towels in order to minimize heat loss. Core body temperature, hand temperature, and $T_{l}$ were recorded at two minute intervals for the next 30 min. Patients then received a bolus of mivacurium $0.08 \mathrm{mg} \cdot \mathrm{kg}^{-1}$ and additional doses were given as needed. Complete recovery was defined as a TOF ratio $>0.90$. Regression analysis plotting $\Delta$ temperature against $\Delta T_{1}$ was performed for each individual. The slope of the regression line for the relationship between $\Delta^{\circ} C$ and $\Delta T_{1}$ was then used to calculate a correction factor (CF) which might be used to "fine tune" the last measured $T_{k}$ The initial hand temperature averaged $30.8 \pm 1.4^{\circ} \mathrm{C}$ and this increased by $4.1 \pm 1.2^{\circ} \mathrm{C}$ over the next 30 min. During this period $T_{1}$ decreased by $24.8 \pm 5.9 \%$ or $-6.05 \% /{ }^{\circ} \mathrm{C}$. The final mean $T_{1}$ value at the end of anaesthesia (uncorrected) was $70.6 \pm 7 \%$ of control. The average corrected $T_{I}$ value was $94.7 \pm 8.5 \%$ (range, $83-111 \%$ ). It is concluded

\section{Key words}

MONITORING: neuromuscular junction, train-of-four, electromyography.

From the Department of Anesthesiology, St. Vincent's

Hospital and Medical Center of New York.

Address correspondence to: Dr. Aaron F. Kopman,

Department of Anesthesiology (Room NR 408), St. Vincent's

Hospital and Medical Center of New York, 153 West 11 th

Street, New York City, NY 10011.

Accepted for publication 4th August, 1995. that there was a correlation between $\Delta^{\circ} C$ and $\Delta T_{1}$ during the first 30 min of anaesthesia $\left(r^{2}=0.77, P<0.0001\right)$. However, in 5 of 15 individuals it was not passible to "temperature correct" the final $T_{l}$ value to within $\pm 10 \%$ of control. Hence, while changes in muscle temperature probably play a major role in the $T_{1}$ driff seen with the Datex monitor, other factors remain to be identified.

La réponse évoquée à l'EMG diminue ordinairement pendant les premières minutes de l'anesthésie. Le but de cette étude était de déterminer la relation possible entre les changements de température de la main qui surviennent à linduction, et la dérive du signal de l'EMG. La réponse indirecte évoquée au ler muscle interosseux dorsal a été mesurée avec un Relaxograph ${ }^{\oplus}$ Datex ${ }^{\circledast}$ chez 15 patients en chirurgie réglée. Le bras servant à l'expérience a été enveloppé dans des serviettes pour en atténuer la perte de chaleur. La température centrale, la température de la main et $T_{1}$ ont été enregistrés aux deux minutes pendant 30 min. Les patients ont alors reçu un bolus de mivacurium $0,08 \mathrm{mg} \cdot \mathrm{kg}^{-1}$ et des doses additionnelles administrées au besoin. La récupération complète a été définie comme un rapport de TOF $>90 \%$. L'analyse de régression établissant la relation entre $\Delta$ température et $\Delta T_{1}$ a été effectuée pour chacun des sujets. La pente de régression pour la relation entre $\Delta^{\circ} \mathrm{C}$ et $\Delta T_{1}$ a été utilisée pour calculer un facteur de correction $(F C)$ utilisable pour une mise au point finale du dernier $T_{1}$ mesuré. La température initiale de la main était en moyenne de $30,8 \pm 1,4^{\circ} \mathrm{C}$. Elle augmentait de $4,1 \pm 1,2^{\circ} \mathrm{C}$ pendant les 30 min suivantes. Pendant cette période, $T_{1}$ diminuait de $28,4 \pm 5,9 \%$ ou $-6,05 \% /{ }^{\circ} \mathrm{C}$. La valeur finale moyenne de $T_{I}$ à la fin de l'anesthésie (sans correction) était de $70,6 \pm 7 \%$ du contrôle. La valeur moyenne corrigée de $T_{1}$ était de 94,7 $\pm 8,5 \%$ (écart, 83-111\%). En conclusion, il existe une corrélation entre $\Delta^{\circ} \mathrm{C}$ et $\Delta T_{1}$ au cours des 30 premières min d'anesthésie $\left(r^{2}=0,77, P<0,0001\right)$. Toutefois, chez cinq des 15 sujets, il a été impassible d'appliquer la correc- 
tion de température à la valeur finale de $T_{1}$ à $\pm 10 \%$ du contrôle. En conclusion, bien que les changements de température musculaire puissent jouer un rôle majeur dans la dérive de $T_{l}$ observée avec le moniteur Datex, les autres facteurs en cause sont encore inconnus.

The use of integrated evoked electromyography (EEMG) as a clinical monitor of neuromuscular block was first described by Lam et al. in 1981, ${ }^{\prime}$ and the first commercial adaptation of this device was described three years later by Pugh et al. ${ }^{2}$ It is now generally accepted that trainof-four (TOF) ratios measured with this technique and those recorded with more traditional mechanical recordings give similar information. ${ }^{3,4}$ There is less agreement on the validity of recordings of single twitch height because of drift of the EEMG amplitude with time. Edmonds et al. ${ }^{5}$ noted many years ago that the EEMG wave-form decreases both in latency and in amplitude during the first few minutes of anaesthesia. At the end of an anaesthetic, it is not uncommon to find that single twitch $\left(\mathrm{T}_{1}\right)$ may only recover to $70-80 \%$ of control despite TOF ratios exceeding 0.90 . This phenomenon has been particularly worrisome since its aetiology has not been elucidated, and the magnitude of the observed drift in $T_{1}$ does not appear to be predictable. Various suggestions regarding the responsible mechanism ranging from an alteration is muscle preload, ${ }^{6}$ to changes in electrode impedance with time, or to some unspecified central effect of general anaesthesia on neuromuscular transmission have been hypothesized, but the cause of this phenomenon has remained uncertain.

Smith $e t a l .^{7}$ reported that induction of anaesthesia is associatec with an increase in hand skin temperature as well as the temperature of first dorsal interosseous (DI) muscle. They found this increase in hand temperature was inversely related to the magnitude of the evoked EEMG of the first DI. However, they were not able to demonstrate a correlation between changes in hand temperature and the extent of $T_{1}$ drift with time.

We decided to reexamine the observations and conclusions of Smith et al. for several reasons. First, the temperature changes they describe averaged about $2^{\circ} \mathrm{C}$ and were accompanied by decreases in $\mathbf{T}_{1}$ of only about $15 \%$ from control. It has been our experience that, if care is taken in wrapping the arm in towels after induction of anaesthesia (passive warming), hand temperature may increase by more than $5^{\circ} \mathrm{C}$, and that under these circumstances much greater decreases in $T_{1}$ may be expected. Second, preliminary observations in our department revealed a correlation between alterations in hand skin temperature $\left(\Delta^{\circ} \mathrm{C}\right)$ and changes in twitch height $\left(\Delta \mathrm{T}_{1}\right)$. If a predictable relationship exists between $\Delta^{\circ} \mathrm{C}$ and $\Delta \mathrm{T}_{1}$, it may be possible to apply a "correlation factor" to EEMG $T_{1}$ values if the final hand temperature as well as the temperature at the time of initial instrument calibration are both known. This study was primarily an attempt to investigate the latter premise.

\section{Methods}

Fifteen ASA PS 1-2, adult patients undergoing elective surgical procedures were included in the study. All patients were free from neuromuscular disease, were within 18 to $65 \mathrm{yr}$ of age, and $15 \%$ of ideal body weight. The protocol was approved by our hospital's Human Subject Review Committee. Anaesthesia was induced with alfentanil $40 \mu \mathrm{g} \cdot \mathrm{kg}^{-1}$ plus propofol $2.0-2.5 \mathrm{mg} \cdot \mathrm{kg}^{-1} i$, and tracheal intubation was accomplished without the use of muscle relaxants. Anaesthesia was maintained with nitrous oxide (65-70\% inspired), propofol 75-100 $\mu \mathrm{g} \cdot \mathrm{kg}^{-1} \cdot \min ^{-1}$, plus fentanyl supplementation $i v$ as needed. Ventilation was controlled, and $\mathrm{PETCO}_{2}$ maintained between 32-38 $\mathrm{mmHg}$. The blood pressure cuff was placed on the contralateral arm, $i v$ lines were in the ipsilateral antecubital fossa.

The indirectly evoked integrated compound action potential of the first dorsal interosseous muscle to supramaximal stimulation of the ulnar nerve at the wrist was measured and recorded using a Datex Relaxograph (-) monitor. Supramaximal nerve stimulation was achieved using the nerve stimulator incorporated into the Datex unit (pulse width $100 \mathrm{msec}$, constant current, 0-70 mA range). The test hand was immobilized, and approximately 200 to $300 \mathrm{~g}$ of resting tension were applied to the thumb with a Velcro strap. Train-of-four stimulation was given every $20 \mathrm{sec}$ during the period of observation, and single twitch depression, indicated by the height of the first TOF twitch/control twitch height $\left(T_{1} / T_{c}\right)$, and TOF fade were continuously recorded. Hand temperature was measured using an Electromedics, Inc. ${ }^{\circledR}$ surface probe (cat. no. 2404, YSI 400 compatible) placed on the palm, just distal to the thenar eminence. This thermistor has an accuracy of $\pm 0.2^{\circ} \mathrm{C}$. All electrodes were applied at least ten minutes before any data collection. Immediately after induction of anaesthesia, control twitch height $\left(T_{c}\right)$ and TOF fade ratio $\left(T_{4} / T_{1}\right)$ were established, and hand temperature was recorded. The test arm was then wrapped in several layers of towels and sheets (from finger tips to the axilla) in order to minimize heat loss. Active warming of the hand was not employed. An oesophageal temperature probe was also placed in order to measure core body temperature. Hand temperature was recorded at two-minute intervals until temperature and $T_{1}$ were stable for at least three minutes $\left( \pm 0.1^{\circ} \mathrm{C}\right.$, and $\pm 1 \% T_{1}$ respectively) or until $30 \mathrm{~min}$ had elapsed from the initial calibration of the Datex ${ }^{\circledR}$ unit. No neuromus- 
cular blocking agents were administered during this 30 min test period. Once the stabilization period was complete, patients received an initial bolus of mivacurium $0.08 \mathrm{mg} \cdot \mathrm{kg}^{-1}$ and additional doses were given as needed clinically. At the end of the surgical procedure, if the TOF ratio had not returned spontaneously to a value of $\geq 0.90$, antagonism of residual block was achieved with increments of edrophonium $0.25 \mathrm{mg} \cdot \mathrm{kg}^{-1}$ until that endpoint was attained.

A scatter diagram was constructed plotting change in hand temperature (independent variable) against any alteration in EEMG (dependent variable). Regression analysis using the method of least squares was performed, forcing the line of regression through the origin. The slopes of the lines of regression ( $\pm 95 \%$ confidence limits) and the coefficient of determination $\left(r^{2}\right)$ were then determined for each individual. Average $\pm S D$ values for these variables were calculated. Similar calculations were also performed using pooled data from all individuals.

The slope of the regression line (pooled data) for the relationship between $\Delta^{\circ} \mathrm{C}$ and $\Delta T_{1}$ was then used to calculate a correction factor (CF) which might be used to "fine tune" the last measured $T_{1}$ value. For example: If the relationship between temperature and twitch height is such that each degree centigrade increase in temperature results in a $6 \%$ decrease in twitch height (slope $=-6.0$ ), then a CF of 1.0638 must be applied $(94 \% \times 1.0638$ $=100 \%$ ). In like fashion, if the hand temperature increased by $3.5^{\circ} \mathrm{C}$ from the time of initial instrument calibration to end of the anesthetic, a CF of 1.2233 would be employed $(1+[3.5 \times 0.0638]=1.2233)$. Hence, if the final $T_{1}$ value at "full" recovery was $81 \%$ of control, the "corrected $\mathrm{T}_{1}$ " would be $99.1 \%(81 \times 1.2233=99.09)$. Corrected $T_{1}$ values were calculated for all patients. The average values and $95 \%$ confidence limits of these values as well as the suggested CF were then calculated. Full $T_{1}$ recovery was defined as return of the TOF ratio to a value $>0.90$.

\section{Results}

\section{Hand temperature and twitch height $\left(T_{\nu}\right)$ vs elapsed time}

Initial palmar skin temperature at the time of instrument calibration (within the first two minutes after induction of anaesthesia) was $30.8 \pm 1.4(\mathrm{SD})^{\circ} \mathrm{C}$. Over the next 25 to $30 \mathrm{~min}$ hand temperature increased by an average of $4.1 \pm 1.2^{\circ} \mathrm{C}$, and stabilized at a value $1.2 \pm 0.4^{\circ} \mathrm{C}$ below core temperature. Approximately $70 \%$ of this temperature change occurred within the first ten minutes after instrument calibration (Figure $\mathrm{l}$ and the Table).

At the time when temperature was deemed to have stabilized, the decrement in $T_{1}$ amplitude averaged 24.8

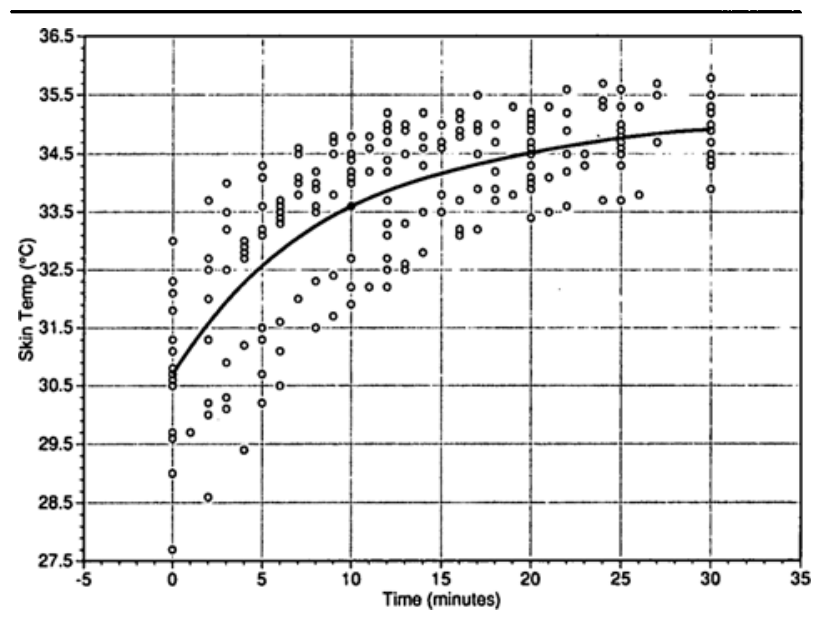

FIGURE 1 Change in palmar skin temperature as a function of time from induction of anaesthesia. Curve fit is the result of a fourth-degree polynomial "best fit" linear least squares analysis. By 25-30 min, hand temperature had stabilized. Data points may overlap.

\pm 5.9 percent from control. At ten minutes postcalibration, $T_{1}$ had decreased by $15.7 \pm 3.9 \%$ or approximately $63 \%$ of the total decrease noted in the first $25-30$ $\min$ (Figure 2).

\section{Hand temperature vs twitch height}

Regression analysis of 208 pooled individual observations from 15 subjects yields a slope for the relationship of twitch height to hand temperature of $-5.61 \% \mathrm{~T}_{1} /{ }^{\circ} \mathrm{C}\left(\mathrm{r}^{2}\right.$ $=0.77, P<0.0001$ ) (Figure 3). The slope as determined by averaging the 15 individually determined temperaturetwitch relationships was $-6.10 \% \mathrm{~T}_{1} /{ }^{\circ} \mathrm{C}(95 \%$ confidence limits, -5.68 to -6.51 ).

At the end of anaesthesia (mean time from initial calibration $=94 \pm 6 \mathrm{~min}$ ), a $\mathrm{CF}$ of $6.5 \% /{ }^{\circ} \mathrm{C}$ was used to correct the final $T_{1}$ values. The final average $T_{1}$ value at the end of anaesthesia (uncorrected) was $70.6 \pm 7 \%$ of control. The average corrected $T_{1}$ value was $94.7 \pm$ $8.5 \%$ (range, $83-111 \%$ ). While there was a correlation between $\Delta^{\circ} \mathrm{C}$ and $\Delta \mathrm{T}_{1}$ during the first $30 \mathrm{~min}$ of anaesthesia, in 5 of 15 individuals it was not possible to "temperature correct" the final $T_{1}$ value at full recovery to within $\pm 10 \%$ of control.

\section{Discussion}

\section{Changes in hand temperature with induction of anaesthesia}

It is now well established that induction and maintenance of general anaesthesia are usually associated with marked peripheral vasodilatation, and a transfer of heat from the body core to peripheral tissues. Matsukawa $e t$ al. demonstrated, under propofol-fentanyl anaesthesia, that fore- 
TABLE

\begin{tabular}{|c|c|c|c|c|c|c|}
\hline Patient \# & $\begin{array}{l}\text { Initial } \\
\text { temp }{ }^{\circ} \mathrm{C}\end{array}$ & $\begin{array}{l}\text { Final } \\
\text { temp }{ }^{\circ} \mathrm{C}\end{array}$ & $\begin{array}{l}\Delta^{\circ} \mathrm{C} \\
\text { at } 30 \text { min }\end{array}$ & $\begin{array}{l}\Delta r_{,}(\%) \\
\text { at } 30 \mathrm{~min}\end{array}$ & $\begin{array}{l}\text { Final } T_{1} \text { as } \% \\
\text { of initial } T_{l}^{*}\end{array}$ & $\begin{array}{l}T_{1} \text { after } C F \dagger \\
\text { Applied (\%) }\end{array}$ \\
\hline 1 & 29.6 & 34.3 & 4.7 & -27.5 & 69 & 103 \\
\hline 2 & 29.7 & 33.8 & 4.1 & -26.0 & 69 & 102 \\
\hline 3 & 31.3 & 35.3 & 4.0 & -31.6 & 58 & 84 \\
\hline 4 & 32.1 & 35.0 & 2.9 & -15.0 & 81 & 99 \\
\hline 5 & 31.8 & 35.5 & 3.7 & -28.0 & 65 & 83 \\
\hline 6 & 30.6 & 34.9 & 4.3 & -30.6 & 65 & 92 \\
\hline 7 & 31.1 & 35.8 & 4.7 & -26.3 & 72 & 91 \\
\hline 8 & 32.3 & 35.0 & 2.7 & -13.3 & 84 & 96 \\
\hline 9 & 30.5 & 34.5 & 4.0 & -22.5 & 72 & 97 \\
\hline 10 & 30.8 & 35.2 & 4.4 & -25.0 & 65 & 93 \\
\hline 11 & 29.0 & 34.3 & 5.3 & -23.5 & 71 & 105 \\
\hline 12 & 30.7 & 34.7 & 4.0 & -21.7 & 76 & 97 \\
\hline 13 & 32.1 & 35.2 & 3.1 & -26.5 & 65 & 85 \\
\hline 14 & 27.7 & 34.7 & 7.0 & -35.4 & 66 & 111 \\
\hline 15 & 33.0 & 35.0 & 2.0 & -19.4 & 80 & 84 \\
\hline Average & 30.8 & 34.9 & 4.1 & -24.8 & 70.6 & 94.7 \\
\hline SD & 1.40 & 0.51 & 1.19 & 5.92 & 7.1 & 8.5 \\
\hline Range & $27.7-33.0$ & $33.8-35.8$ & $2.0-7.0$ & $-13-(-) 35$ & $58-84$ & $83-111$ \\
\hline
\end{tabular}

*In all cases, TOF ratio $\geq 0.90$.

†Correction factor $(\mathrm{CF})=+6.5 \%$ per $\Delta^{\circ} \mathrm{C}$ decrease.

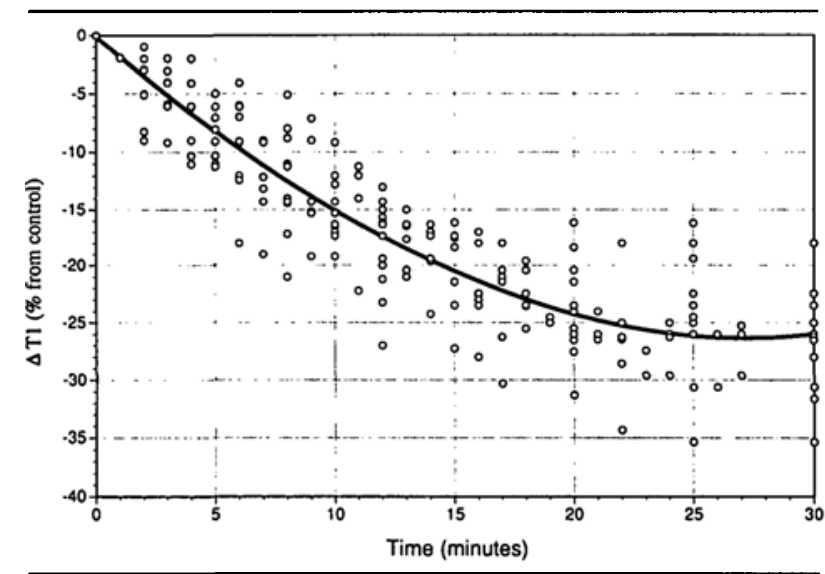

FIGURE 2 Change in indirectly evoked single twitch amplitude $\left(T_{1}\right)$ as a function of time from induction of anesthesia. Curve fit is the result of a fourth-degree polynomial "best fit" multiple linear least squares analysis. By $25-30 \mathrm{~min}, \mathrm{~T}_{1}$ had stabilized. Data points may overlap.

arm blood flow increases on average by more than fourfold with induction of anaesthesia. ${ }^{8}$ Smith $e t$ al. ${ }^{7}$ demonstrated that following induction with propofol and maintenance with nitrous oxide and enflurane that the temperature of the first dorsal interosseous (first DI) muscle will increase by $2^{\circ} \mathrm{C}$ during the first $30 \mathrm{~min}$ of anaesthesia. Despite stable nasopharyngeal temperatures (mean 36.0 , range $35.9-36.2^{\circ} \mathrm{C}$ ), the temperature of the first DI rose from $33.5^{\circ} \mathrm{C}(33.1-33.9)$ to $35.5^{\circ} \mathrm{C}$ (35.3-35.8) during that interval. We have now docu-

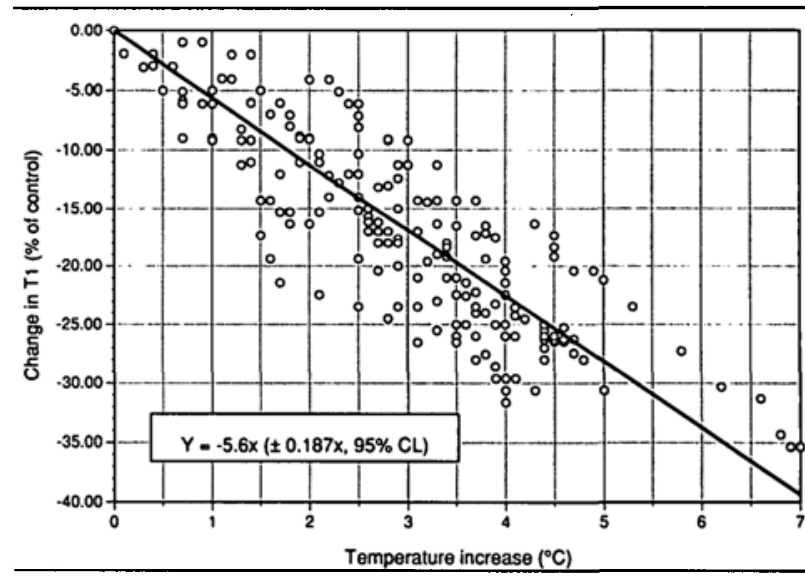

FIGURE 3 Change in indirectly evoked single twitch amplitude $\left(T_{1}\right)$ as a function of time from induction of palmar skin temperature. Linear least squares analysis. The coefficient of determination $\left(r^{2}\right)$ was $0.77(P<0.0001)$. Data points may overlap.

mented that, if some attempt is made to insulate the arm from the ambient environment, increases in hand temperature of $\geq 4.5^{\circ} \mathrm{C}$ are not uncommon.

A potential pitfall in our study was that muscle-skin temperature gradients probably were not constant during the initial $30 \mathrm{~min}$ of observation. The gradient between skin and muscle temperature is difficult to predict. Heir et al. ${ }^{9}$ found that skin temperature averaged $2.2^{\circ} \mathrm{C}$ below muscle temperature, which in turn was $0.8^{\circ} \mathrm{C}$ below core temperature. However, it appears that in that investigation 
the hand under study was exposed to ambient operating room temperatures. Our initial measurement of skin temperature was made with the hand exposed to room air. Subsequent temperature determinations were made after wrapping the arm and hand in several layers of cotton blankets. Hence, while average skin temperature increased by $4.1^{\circ} \mathrm{C}$ during the initial $30 \mathrm{~min}$ of observation, it is possible that changes in muscle temperature were less dramatic. While we recognized this difficulty in advance, our goal was to validate a noninvasive approach to EMG monitoring, and we elected not to place im temperature probes.

\section{Changes in $T_{1}$ with time}

When determining "baseline" or control values for evoked muscle twitch amplitude it is necessary to establish that these values are stable over time. Failure to establish baseline stability presents the researcher with potential difficulties. For example, if an investigator wishes to administer an anticholinesterase antagonist at $25 \%$ recovery of $T_{1}$, the extent to which the control value has "drifted" over time is unknown. Hence, it is not possible to determine the correct time to induce reversal. If, following complete reversal (no fade on TOF stimulation), $T_{1}$ returns to only $80 \%$ of control, it is apparent that drugs given at " $25 \%$ recovery" were in fact administered at $31 \%$ of control.

The need for a period of baseline stabilization is not unique to electromyography. When recording mechanical responses to indirect stimulation, a different problem is encountered. It has been known for many years that the force of twitch tension will increase with repeated stimulation. This is known as the staircase phenomenon or treppe. ${ }^{9}$ Thus, when performing mechanomyographic (MMG) studies, twitch height tends to increase with time. The extent of twitch augmentation is a function of stimulation frequency and the total number of stimuli applied. Generally, however, a stable mechanomyographic "preparation" can be assured if the nerve-muscle unit is first conditioned by $1 \mathrm{~Hz}$ stimulation for two to three minutes (Savarese JJ, personal communication). The need to spend more than five minutes establishing a stable baseline is usually unnecessary when doing MMG studies.

The magnitude of the indirectly evoked mechanical twitch response is not immune to changes in muscle temperature. Heier et al. observed that $T_{1}$ did not decrease until muscle temperature decreased below $35.2^{\circ} \mathrm{C}$. Below this temperature twitch tension decreased in a linear manner. ${ }^{10-12}$ Similarly, Erikkson et al. reported that prolonged TOF nerve stimulation did not change the mechanical twitch response in patients with a normal central and peripheral temperature. A peripheral skin temperature $<32.0^{\circ} \mathrm{C}$ with sustained and normal body tem- perature is, however, associated with changes in both twitch tension and TOF ratio that may be a source of error when evaluating neuromuscular function. ${ }^{13}$

There is mounting evidence that the EMG is also greatly influenced by muscle temperature. While decreases in muscle temperature are associated with a reduction of isometric force, this is accompanied by an increase in the peak-to-peak amplitude of the compound action potential. ${ }^{14}$ Engbaek et al. ${ }^{15}$ also found that the EEMG signal was highly temperature dependent. They reported (in an animal model) that a $1^{\circ} \mathrm{C}$ decrease in muscle temperature was associated with a $6 \%$ increase in $T_{1}$ from control levels. They suggested that the failure of the EEMG to return to $100 \%$ of control during clinical studies might be in part due to changes in muscle temperature.

It was our hypothesis at the start of this investigation that these temperature changes were the dominant cause of the drift seen in the EEMG when employing the Datex monitor. While in general we did find a correlation between $T_{1}$ drift and temperature, we were unable in any specific patient to apply a temperature correction factor with any confidence. In five of 15 individuals it was not possible to "temperature correct" the final $T_{1}$ value at full recovery to within $\pm 10 \%$ of control. The extent of this uncorrected "drift" in $T_{1}$ was not a function of time since calibration, and was unrelated to any other modifying factor that we could identify.

In view of the above findings, investigators using the Datex Relaxograph to record changes in $T_{1}$ should report the conditions under which their data were obtained in detail. How long was the period of signal stabilization? What was the hand temperature at the time control responses were recorded? To what extent did hand temperature change during the period of observation? Did $T_{1}$ return to control at the end of the observation period? What was the TOF ratio at the time when $T_{1}$ was determined to be fully recovered? If $T_{1}$ did not return to $100 \%$ of control at a time when the TOF ratio had recovered to a value $\geq 0.90$, how did the investigator "normalize" the data? Unless answers to these questions are provided, meaningful interpretation of the investigator's data may not be possible.

\section{References}

1 Lam HS, Cass NM, Ng KC. Electromyographic monitoring of neuromuscular block. Br J Anaesth 1981; 53: 1351-7.

2 Pugh ND, Kay B, Healy TEJ. Electromyography in anaesthesia. Anaesthesia 1984; 39: 574-7.

3 Kopman AF. The dose-effect relationship of metocurine: the integrated electromyogram of the first dorsal interosseous muscle and the mechanomyogram of the adductor pollicis compared. Anesthesiology 1988; 68: 604-7. 
4 Engbaek J, Qstergaard D, Viby-Mogensen J, Skovgaard LT. Clinical recovery and train-of-four ratio measured mechanically and electromyographically following atracurium. Anesthesiology 1989; 71: 391-5.

5 Edmonds HL, Paloheimo M, Wauquier A. Computerized EMG monitoring. Applications in anesthesia and intensive care. Schoutlaan, The Netherlands: Malherbe Publishing Co, 1988; 48-9.

6 Kopman $A F$. The effect of resting muscle tension on the dose-effect relationship of d-tubocurarine: does preload influence the evoked EMG? Anesthesiology: 1988; 69; 1003-5.

7 Smith DC, Booth JV. Influence of muscle temperature and forearm position on evoked electromyography in the hand. Br J Anaesth 1994; 72: 407-10.

8 Matsukawa T, Sessler DI, Sessler AM, et al. Heat flow and distribution during induction of general anesthesia. Anesthesiology 1995; 82: 662-73.

9 Krarup C. Enhancement and diminution of mechanical tension evoked by staircase and by tetanus in rat muscle. $J$ Physiol 1981; 311: 355-72.

10 Heier T, Caldwell JE, Eriksson LI, Sessler DI, Miller RD. The effect of hypothermia on adductor pollicis twitch tension during continuous infusion of vecuronium in isoflurane-anesthetized humans. Anesth Analg 1994; 78: 312-7.

11 Heier T, Caldwell JE, Sessler DI, Kitts JB, Miller RD. The relationship between adductor pollicis twitch tension and core, skin, and muscle temperature during nitrous oxide-isoflurane anesthesia in humans. Anesthesiology 1989; 71: 381-4.

12 Heier T, Caldwell JE, Sessler DI, Miller RD. The effect of local surface and central cooling on adductor pollicis twitch tension during nitrous oxide/isoflurane and nitrous oxide/ fentanyl anesthesia in humans. Anesthesiology 1990; 72 : 807-11.

13 Eriksson LI, Lennmarken C, Jensen E, Viby-Mogensen J. Twitch tension and train-of-four ratio during prolonged neuromuscular monitoring at different peripheral temperatures. Acta Anaesthesiol Scand 1991; 35: 247-52.

14 Hopf HC, Maurer K. Temperature dependance of the electrical and mechanical responses of the adductor pollicis muscle in humans. Muscle Nerve 1990; 13: 259-62.

15 Engbaek J, Skovgaard LT, Friis B, Kann T, VibyMogensen J. Monitoring of the neuromuscular transmission by electromyography (I). Stability and temperature dependence of evoked EMG response compared to mechanical twitch recordings in the cat. Acta Anaesthesiol Scand 1992; 36: 495-504. 